\title{
Neuromarketing - The Potential Tool for Sales of Aesthetic Lasers
}

\author{
P. Malarvizhi, T.R. Suresh Kumar
}

\begin{abstract}
Marketing began in 1920s during economic prosperity as the supply was greater than demand. Industries started innovations to sell their products to unwilling customers in the scientific manner analyzing the consumer behaviors. Scientific analysis and research spread towards many fields, from economics to medicines, engineering and marketing, leading to new disciplines, such as Neuro economics, Neuro designs and Neuromarketing. Neuromarketing is the integration or coming together of distinct and separate factors or convergence of evolutionary biology, psychology, genetic, neuroscience, with marketing and economics. Neuromarketing is gaining momentum and the brain science is ruling the market for the consumer buying behavior. In the last two decades, cognitive neuroscience and psychology has made progress in the study of the human mind and behavior. Neuro design" provides the knowledge on the functioning of the human brain for the design of more effective products, size, colours, packaging etc. This paper emphasizeNeuromarketing as an effective marketing tool for sales of aesthetic laser products, so as to make products and messages more effective. Neuromarketing is everything in understanding the design cues and aesthetics, that appeal to human beings' inner truths and sensibilities, which formed a lakh year ago. Therefore, in this study, the researcher has highlighted the opinion of the field experts that neuro variables play a decisive role in the minds of customers while choosing and buying aesthetic products.
\end{abstract}

Key Words: Neuromarketing, Aesthetics, Lasers, Sales, Customers

\section{INTRODUCTION}

Neuromarketing is the research of neuroscience, measuring of neuro signals of the brain. Marketing researches has created a need for new method of marketing resulting in reliable, more accurate, and knowledge, to make better business decisions. Neuromarketing is crossing the line between influence and manipulation All marketing is Neuromarketing, as "Everything is Chemistry", since all living and nonliving things are made up of molecules. "Neuroculture" is the current age of living where neuro scientific knowledge is constantly incorporated into people's life, culture, and intellectual discourses. Neuromarketing includes an "emotional impact of branding", public understanding which indicates that the main objective of neuro marketing is to "decipher the processes that take place inside the mind of consumers in order to discover the wishes, aspirations and hidden springs of their options and to be able to provide them with what they want". In this context,

Revised Version Manuscript Received on August 19, 2019.

Dr. P.Malarvizhi, Assistant Professor, Post Graduate and Research Department of Commerce, Chevalier.T.Thomas.Elizabeth College for Women, Chennai, Tamilnadu, India(Email: : malar_mvs@yahoo.co.in)

Mr. T.R. Suresh Kumar, Sales Manager - South India, Laser Division, Timpac Healthcare Pvt. Limited, Chennai, Tamilnadu, India(Email: : trskumar13@gmail.com)
Psychiatry plays role in functional magnetic resonance imaging (FMRI) and other neuro technologies. Neuromarketing includes brain activity measurement technology like magneto encephalography, electrocardiography, electromyography, eye tracking, galvanic skin response and analysis of pupil dilation, blush, blinking, heartbeat, or breathing and etc.

Human beings are influenced by the emotions, psychology, reasons and stimulus or instincts and it all determines the consumer's sales behavior. Purchase or preference is mostly an emotional activity by brain which rationalizes later. Top brands are subconsciously or consciously using the notion of neuro marketing to implement marketing tactics in order to stimulate emotional connections and advertise to the consumer by creating or recalling positive memories. Medical Laser market size is expected to reach $\$ 19.4$ billion by 2023 , growing at the annual rate of $12.2 \%$ globally. Medical aesthetics is a branch of scientific research that uses minimal invasive procedures which help in improving a person's physical appearance, through the use of healthcare and cosmetic services in combination with lasers or other energy based devices like RF-Radiofrequency, Ultrasound, MNRFmicro needling radio frequency, Cool sculpting, Liposuction and etc.. India is set to dominate the global market in the future, but is currently the $2^{\text {nd }}$ biggest market in the APAC region behind China. The growth of medical aesthetic market determines by the advancement in laser technology from surgical to non surgical procedures, various health benefits. But challenges like high treatment cost and lack of reimbursements, and cosmetic boom is likely to impede the growth.

\section{NEED FOR THE STUDY}

Aesthetic Dermatology is showing the fastest sales growth, $17.5 \%$ in India with a compounded annual growth rate of five year in the pharma retail market, even higher sales than the sales growth witnessed in anti-diabetes or heart disease pills. Indians are virtually turning the age old adage that beauty is only skin deep on its head. In this context, it is necessary to untap the potentiality of neuromarketing techniques for sale of aesthetic lasers. Therefore, in this study, the researcher has highlighted the opinion of the field experts that neuro variables play a decisive role in the minds of customers while choosing and buying aesthetic products. 


\section{OBJECTIVES OF THE STUDY}

1. To explain the role played by neuro variables in influencing buying decisions

2. To study the impact of neuro marketing while choosing aesthetic products

\section{LIMITATIONS OF THE STUDY}

1. Restricted to Chennai city

2. Restricted to marketing of aesthetic laser products.

\section{REVIEW OF LITERATURE}

WilliemKottier, "The added value of Neuromarketing tools in the area of marketing research", indicates a positive contribution of neuromarketing tools to the aspects of identifying the customers' needs and wants and to all four aspects of the integrated marketing program: product, price, distribution and promotion.

Zara I.A. and Tuta M., " Review paper of neuromarketing research", has highlighted some commonly used methods in Neuromarketing studies as MEG (Magneto encephalography), EEG(electroencephalogram) and FMRI(functional magnetic resonance imaging). Non-neurological methods and biometrics analysis like heart rate and respiratory rate, galvanic skin response, eye-tracking, facial, body and voice tracking are being used in neuromarketing studies.

\section{RESEARCH METHODOLOGY}

The researcher has used both primary data and secondary data. Primary data was collected through Judgment sampling, selecting 50 respondents represented by aesthetic laser consultants, cosmetologists and plastic surgeons from Chennai city. Secondary data was collected by googling from the websites. Simple percentage method is used to interpret the collected data.

\section{ANALYSIS AND INTERPRETATIONS}

Neurons in the brains are the nerve centre which transmits messages to other parts of the body to perform functions. The two neuro transmitters that affect human beings creativity are seraton in and dopamine. The neuro transmitter Dopamine is responsible for motivation, emotional arousal, reward, pleasure and etc. More the dopamine in the brain, the person will be more intellectual and creative.

The physiological analysis tests such as EEG(electroencephalogram)-electric impulses on the surface area of the brain, FMRI(functional magnetic resonance imaging)-oxygenated blood flow into different areas of brain , Biometrics-heart rate, skin conduction, motion and respiration, Eye-tracking-precise visual response to stimuli and Facial coding-micro expressions measure primary metrics such as emotional engagement, memory attention, and derived metrics such as purchase intent persuasion, awareness/understanding/comprehension, novelty , in response to brand, product, packaging, advertising, in-store stimuli with neuromarketing, predict the likelihood that someone will remember something after exposure to stimuli. It will help to study the process of memory influencing attitudes, decisions and behaviours without entering conscious thought.
The brain recognizes body proportions, features of face, eyes thereby tuned to the Human Brand. If one knows how the decision-making part of the brain works, then he or she can quickly begin to deliver more convincing sales presentations, close more deals, create more effective marketing strategies, and radically improve their ability to influence others. The brain is responsible for all consumer behaviors in decision making process. it needs to use a lot of energy to function properly. Even though the brain is only $2 \%$ of the body mass, it burns nearly $20 \%$ of energy. Most of the functions that one goes through a day are managed by the brain below the level of consciousness. Nearly $80 \%$ of the brain energy is necessary to sustain default mode or rest state, a critical aspect of brain functioning which continues to puzzle neuroscientists. We Human being only uses about $20 \%$ of brain consciously.

Aesthetics industry has successfully created a revolution in the Indian wellness market. With the advent of technologies, aesthetic surgery have proved medical benefits, myths has been broken on seeing celebrities, increased awareness made options available for permanent self-beautification, fascination of medical spas and clinics made the cosmetic industry booming.

Different segments of Aesthetic lasers market - Type, Applications and End user:

\section{Type -}

Aesthetic lasers type market is classified into multiplatform lasers and standalone lasers. In India multiplatform lasers are the fastest-growing segment because it provides scalable and upgradeable hybrid systems that can treat multiple indications. Aesthetician provides combination therapy to treat a single indication or multi indications in a single package contributing to the higher growth of this segment.

\section{Application -}

On application segment, the aesthetic lasers type market is classified into Hair removal, skin rejuvenation, acne scars,vascular lesions, pigmented lesions \& tattoos removal and etc. The hair removal and skin rejuvenation segments are accounted for the largest share of the market because of aesthetic procedures, increased focus on body appearance and laser technologies.

\section{End Users -}

On end user, the aesthetic lasers type market is segmented into Clinics, Hospitals and Spas. Due to the increasing awareness and benefits of aesthetic procedures, minimal invasive surgeries, private clinics segments are accounted for the largest share of the market and it is burgeoning. 


\section{FINDINGS \& RESULTS}

The opinion of the aesthetic consultants, cosmetologists and plastic surgeons in Chennai city regarding few neuromarketing variables are summarized as follows:

\begin{tabular}{|c|c|c|c|c|c|c|c|c|c|c|c|c|c|}
\hline S.N & \multirow[t]{2}{*}{ Variables } & \multicolumn{2}{|c|}{ SA } & \multicolumn{2}{|c|}{$\mathbf{A}$} & \multicolumn{2}{|c|}{$\mathbf{N}$} & \multicolumn{2}{|c|}{ DA } & \multicolumn{2}{|c|}{ SDA } & \multicolumn{2}{|c|}{ Total } \\
\hline $\mathbf{0}$ & & No. & $\%$ & No. & $\%$ & No. & $\%$ & No. & $\%$ & No. & $\%$ & No. & $\%$ \\
\hline 1. & $\begin{array}{l}\text { There is increasing beauty } \\
\text { consciousness among the general } \\
\text { public }\end{array}$ & 32 & 64 & 8 & 16 & 10 & 20 & - & - & - & - & 50 & 100 \\
\hline 2. & $\begin{array}{l}\text { Neuromarketing plays more in } \\
\text { cosmetic practice in the } \\
\text { subconscious mind of customers }\end{array}$ & 46 & 92 & 4 & 8 & - & - & - & - & - & - & 50 & 100 \\
\hline 3. & $\begin{array}{l}\text { Short, impactful statements are } \\
\text { more likely to stick to customers }\end{array}$ & 40 & 80 & 7 & 14 & - & - & 3 & 6 & - & - & 50 & 100 \\
\hline 4. & $\begin{array}{l}\text { Photos and visual presentations are } \\
\text { better at selling products than words }\end{array}$ & 45 & 90 & 5 & 10 & - & - & - & - & - & - & 50 & 100 \\
\hline 5. & $\begin{array}{l}\text { Appeal to emotion is effective than } \\
\text { intellect or reason }\end{array}$ & 45 & 90 & 3 & 6 & 2 & 4 & - & - & - & - & 50 & 100 \\
\hline
\end{tabular}

\section{SA - Strongly Agree, A-Agree, N-Neutral, DA-Disagree, SDA-Strongly Disagree}

From the above table, it is found that:

- Increasing beauty consciousness among the people paves broad way and holds potential scope for effective marketing of aesthetic laser products.

- As beauty is more of a psychological concept, though it is perceived as a physiological one, $92 \%$ of the respondents strongly agree that neuromarketing plays more in cosmetic practice in the sub conscious mind of the customers.

- $80 \%$ of the respondents opine that short, impactful statements are more likely to stick to customers amidst their fast paced, time deprived life style. The average person has an attention span of 8 seconds only. Always let it be simple and precise. Clever abstractions or too many numbers will only confuse consumers. Anywhere from 30 to $70 \%$ of the time, it is not possible to have someone's full attention, online or offline.

- Marketing appeal is greater with photos and visual presentations as $90 \%$ of the respondents found them to be better at selling products than words. In general, $65 \%$ of people are visual learners. As brain tends to remember beginnings and endings rather than middles, it is always better to start of strong and end with big visual appeals. Human beings process visuals 60,000 times faster than text .

- $90 \%$ of the respondents are of the opinion that appeal to emotion is effective than intellect or reason. This once again substantiates the fact that beauty is more of a psychological concept and neuromarketing is effective in targeting at it. An emotional response is everything, without it, marketing and advertising do not resonate.

\section{SUGGESTIONS:}

As revealed by the above findings, neuro variables such as beauty consciousness, photos and visual presentations, plays a significant role in influencing the decisions of the customers while buying aesthetic products.

As appeal to emotion is more effective than intellect or reason, impact of Neuromarketing should be greater than any other variable, while selling aesthetic products.

India being a developing country, in the last one decade aesthetic market is booming and growing at a faster pace. While young doctors prefer aesthetic practice not only in metros but also in tier two and three cities, there is ample scope for using Neuromarketing variables to influence the customers' choice and buying decisions related to aesthetic products. Innovation is more than just a new design.

\section{CONCLUSION}

Neuromarketing is the only alternative to the study of economic human behavior because it depicts "consumer real feelings, not what he says he feels". Neuromarketing can provide more reliable information for decision-making of marketing managers, which promotes a better understanding of customer's needs. Indian industry trends such as increasing consolidations of manufacturers, social media marketing and suppliers of aesthetic lasers products is further driving the growth of this market. Thus, 'BRAIN IS UNIVERSAL' for the good of science...it's a new horizon in marketing of aesthetic lasers. 


\section{REFERENCES}

1. Review Paper Neuromarketing Research - A Classification and Literature Review Zară I.A. and Tuţă M. Faculty of Marketing, Academy of Economic Studies, Bucharest, ROMANIA Available online at: www.isca.in Received 25th March 2013, revised 8th May 2013, accepted 11th July 2013

2. Aesthetic/Cosmetic Lasers Market by Type (Standalone (CO2, Er:YAG, Diode, Nd:YAG, Alexandrite, Pulsed-Dye), Multiplatform), Application (Acne, Scars, Tattoo Removal, Varicose Veins), End User (Hospitals, Medical Spa, Private clinics) - Forecasts to 2021

3. http://iiespace.iie.ac.za/bitstream/handle/11622/85/Angel ique $\% 20$ Farinha-1.pdf?sequence $=1 \&$ is Allowed $=y$

4. https://www.ncbi.nlm.nih.gov/pmc/articles/PMC3152487 I

5. https://www.mordorintelligence.com/industry-reports/ind ia-aesthetic-devices-market

6. https://www.psmarketresearch.com/market-analysis/medi cal-aesthetics-market

7. http://www.isca.in/rjirs/archive/v2/i8/15.ISCA-RJRS-201 3-147.pdf

8. https://www.bestmarketingdegrees.org/neuromarketing/

9. https://www.packagingdigest.com/packaging-design/neur odesign-the-new-frontier-of-packaging-and-product-desi gn1510 